\title{
Developing local library and information services
}

It fell to me to review the services we provide in our hospital library in Perth, which in turn lay behind my decision to stand for election to the post of Librarian of the Royal College of Psychiatrists. This has involved oversight of developing services for our members and others, and this paper is a response to a request often made to us - what advice can we give to those reviewing their own services? This paper is far from being a solo effort, the professional staff of the College Library and Information Service, and what we dubbed the Virtual Library Committee (colleagues representing faculties and other interests, who have advised us in cyberspace), deserve much of the credit.

Responsibility does, however, rest with me. It is my own perception of why we should have such services locally, what sort of thing such a service might be, and where, who should hold responsibility for it, how he or she might be supported, and, perhaps most importantly, how to keep a service up to date. This last point requires particular emphasis as e-publishing and e-psychiatry grow relentlessly.

\section{Why have a local service at all?}

Why not depend upon a local university service, upon the Royal College of Psychiatrists, upon National Health Service e-libraries, upon the British Medical Association or the Royal Society of Medicine for their members and fellows? I believe the answer is at least fivefold.

- Many of us are lethargic (if we are honest) or extremely busy (if we seek to rationalise), which suggests that the simple fact of a service being off-site will discourage us from using it.

- We should seek to promote a general spirit of enquiry in our services.

- We should support the day-to-day scientific work of our colleagues, for example the consultant who takes on responsibility for electroconvulsive therapy (ECT) or, more ambitiously, initiates or participates in research.

- We should support the scientific component of training - the senior house officer's audit, the specialist registrar's research.

- And increasingly we must be able to match our patients' web-based knowledge.

\section{What functions might local services provide?}

The physical space is important - it is not the clinic, it is not the ward. This creates the mental space necessary for reflection and study. The material for this comprises journals, textbooks and an electronic infrastructure.
- It may sound parochial but it would be odd if the Royal College of Psychiatrists did not recommend its own journals, particularly because of their contrasting and complementary content. The British Journal of Psychiatry represents science, the Psychiatric Bulletin, practice and Advances in Psychiatric Treatment, review.

- I believe it is short-sighted to restrict journal subscriptions to those specialties represented on site, as trainees need to know about all areas of psychiatry for examination purposes, senior medical staff need that same knowledge to practise, as the patients we see are not necessarily the ones we expect.

- I believe there is value in subscribing to non-UK journals; with increasing centralist jurisdictions in the UK it is well to remember that others think and practise differently.

- Is the textbook dead? I think not - we certainly need reference texts (for example works on paediatrics in a child and adolescent mental health service); can we imagine a library without Lishman's Organic Psychiatry? Some books are primarily about ideas (particularly in psychotherapy), others will represent particular local expertise and interests.

- Journals may be available electronically instead of, or as well as, hard copy, and increasingly textbooks can be accessed online. Space and cost will determine how these will be purchased.

- If a book list is rapidly out of date then a firm recommendation about hardware and software will be doubly so; I shall restrict myself to principles. When we interview our patients about their drinking habits we are encouraged to double what they admit to, the same principle applies to computer terminals double the number you think you need; as ever, the faster the chip, the better; broadband wins out over ordinary phone lines; heavy duty printers will almost cer tainly pay for themselves in reliability and longevity.

\section{Where might these libraries be?}

We shall lose ours in Perth. It is presently situated in a $80 \mathrm{~m}^{2}$ room, housing 1500 books and bound volumes of 15 journals on the same floor as what was originally the hospital ballroom! But this magnificent 1827 Georgian building is destined for closure, bizarrely 'fit for purpose' for conversion to flats our staff will never be able to afford, but apparently not 'fit for purpose' for staff to work in. At the same time, we are opening small community bases in Perth City and its rural hinterland. This must surely echo increasing dispersal of service provision elsewhere in the UK, and there are no easy answers as to how to provide dispersed library services. Perhaps a hub-and-spoke model is most appropriate - 
central provision for the librarian, with 'bench libraries' tailored to individual circumstances elsewhere, perhaps supported by that same librarian on a peripatetic basis.

special articles and our recommendations for journals, books and databases can now be found on the Royal College of Psychiatrists' website. We can keep ourselves up to date by sharing our ideas; we can only solve our problems by asking others for solutions; we have the potential means to do so via feedback on these recommendations to the Library and Information Service within the Royal College of Psychiatrists.

Somebody has to do it. When I was Clinical Director counted the number of consultants and the number of extra jobs - with three main sites in a 3000 square mile patch we have three consultants with responsibility for ECT, three psychiatric tutors, a full set of specialty tutors, clinical governance leads, etc. Matching this with the total number of consultants meant that for most of the time most consultants will undertake one such duty, and over the course of their careers will undertake several. Responsibility for a library is a further post to be added to the pot and, like the others, offers contrast to clinical work, and the opportunity for the incumbent to add both specialist skills, and more general skills, which may be applied in other settings. As with other posts a consuming interest in the subject may be less important than energy and enthusiasm.

\section{Who else?}

The help of a professional librarian is essential, but the amount of contracted time needed may be surprisingly modest. Our trainees frequently use our bigger central library as it is on the same premises as their MRCPsychiatry course; specialist registrars and consultants involved in research often use the university departmental library; our local needs are met by a librarian working two mornings each week. It does not require too much self-discipline to come in on these mornings if one needs to see the librarian in person; if not, then a note of one's requirements will be met with their landing in one's tray a week or so later. But without such support the value of the library will be seriously compromised.

You should avoid any risk of your decisions being unsoundly based, you will not be confident in your knowledge of the breadth of psychiatry nor in technological advances. Depending on your frame of mind you may wish to convene a library committee, or a less bureaucratic individual may be content to network with his/her colleagues, cross-checking with colleagues in neighbouring mental health services, or in primary care or acute hospitals locally. Advice is readily available from the Royal College of Psychiatrists' Information Services Officer, Morwenna Rogers, or myself, the College Librarian, Dr David Tait.

\section{Keeping up to date}

Almost by definition this will be electronic. This paper is a step towards helping current services get up to speed,

\section{Epilogue - toolkit for a would-be 'Library Consultant'}

- Volunteer today, do not wait for someone else to do so first.

- Establish your role within your job plan so that your employer takes it seriously, and you set a precedent for your successor.

- Establish a budget, and if the management is obstructive, offer that well-known aphorism 'if you think education is expensive, try ignorance'.

- Establish premises, and if the management is obstructive, suggest that intellectual functions are as important as bodily functions - libraries are necessary, just like toilets

- Appoint a professional librarian, part-time work may suit the domestic circumstances of some applicants, sharing a full-timer with another institution may be an option.

- Seek participation - a library committee? Involve other disciplines? Write a newsletter?

- Make public your expectations - the price for the successful request of a book is to write a review, for the successful request of a subscription is to present papers from it to the journal club.

- Use our web-based suggestions as you think fit, contact us with your feedback (mrogers@rcpsych.ac.uk; dtait@rcpsych.ac.uk).

- And have fun - I greatly enjoyed turning our local library around, I greatly enjoy being College Librarian, who knows what doors may open for you?

\section{Acknowledgements}

College Staff: Morwenna Rogers, Margaret Harcourt Williams, Laura Hulse, Alex Cohen; Virtual Library Committee: Robert Baldwin (Old Age), Peter Carpenter (Learning Disabilities), Kevin Craig (Collegiate Trainees' Committee), Ed Day (Substance Misuse), Michele Hampson (General and Adult), George Ikkos (personal interest), Chris Murphy (Basic Training Specialist Committee), Douglas Turkington (Psychotherapy), Cleo Van Velson (Forensic), James Walters (Collegiate Trainees' Committee), Moris Zwi (Child and Adolescent).

David Tait Librarian, Royal College of Psychiatrists, 17 Belgrave Square, London SW1X 8PG 